\title{
Blends of polyamide-6 with acrylic core-shell impact modifiers
}

\author{
R. J. Gaymans* and J. W. van der Werff $\dagger$ \\ Department of Chemical Engineering, University of Twente, PO Box 217. \\ 7500 AE Enschede, The Netherlands \\ (Received 6 May 1993; revised 16 July 1993)
}

\begin{abstract}
Blends of polyamide-6 (PA6) and acrylic core-shell impact modifiers (CSIM) were made by an extruder process as well as a reactor process. On the extruder blends, the impact behaviour was studied as a function of temperature while changing the type of CSIM, the CSIM concentration $(0-40 \%)$ and the blending conditions. Reactor blends were prepared from caprolactam/CSIM mixtures via a hydrolytic polymerization process initiated either with water or with aminocapronic acid. The aminocapronic acid-initiated process is faster. The influence of reaction conditions on the deagglomeration of the CSIM, the melt flow index and the impact behaviour of the blends were studied. The degree of grafting of PA6 on the CSIM and the melt rheological behaviour of some samples have been investigated. The CSIM agglomerates were found to be broken up in the caprolactam starting mixture and did not coalesce to bigger particles. With the reactor blend method, often highly viscous melts were obtained. This is probably due to the formation of a comb-like structure of CSIM chains dissolved in caprolactam to which PA6 chains had been grafted.
\end{abstract}

(Keywords: polyamide-6 blends; core-shell acrylic rubber; impact behaviour)

\section{INTRODUCTION}

Polyamides (PA) can be toughened by blending with rubber $^{1-3}$. The notched Izod impact behaviour of these blends as a function of temperature shows two transitions as schematically presented in Figure 1. One is at the glass transition of the rubber, where the rubber becomes soft and can act as an impact modifier. The other is at the so-called brittle-to-tough transition temperature $\left(T_{b}\right)$. At this transition the fracture process changes from unstable to stable crack propagation. The parameters that affect this brittle-to-tough transition are the rubber concentration $^{3}$, the particle size $\mathrm{s}^{3,4}$, the type of rubber ${ }^{5}$ and the molecular weight of the matrix material ${ }^{6}$. PA blends are usually made by reactive compounding. For this, rubbers are usually acid-modified to make grafting of PA chains onto the rubber particles possible. The surface grafts lower the interfacial tension, prevent coalescence and hence stabilize the dispersion. The rubber particle size changes with the blending conditions. For the impact behaviour, the optimal particle size for the PA systems is in the $0.2-0.3 \mu \mathrm{m}$ range 4 .

Instead of using a rubber that has to be broken up in the blending process, it is also possible to work with preshaped particles. These materials are supplied as watery emulsions or as precipitated agglomerates. To prevent the rubbery particles fusing together, they are given a hard shell. In the blending process these core-shell impact modifiers (CSIM) have only to be deagglomerated. Extrusion blends with CSIM give good

\footnotetext{
* To whom correspondence should be addressed

+ Presently at General Electric Plastics, PO Box 117, 4600AC Bergen op Zoom. The Netherlands
}

$0032-3861 / 94 / 17 / 3658-07$

(C) 1994 Butterworth-Heinemann Ltd

POLYMER Volume 35 Number 171994 impact behaviour ${ }^{7,8}$. The core-shell impact modifiers are frequently used in the toughening of polyesters.

The formation of toughened systems by a reactor process has been studied ${ }^{9-12}$. For optimum properties, the morphology of the reactor blends should be comparable to that of extrusion blends. The particle size of the rubber should be small and uniform and the rubber should remain rubbery. In a reactor no high shearing can be applied, and so in the reactor process a high-viscosity rubber cannot be broken up. To obtain a fine dispersion, other methods should be applied. The polymerization conditions limit the reactor blending process.

The synthesis of polyamide-6(PA6) is usually hydrolytic, starting from caprolactam (CL) with water as initiator (few per cent). The slowest step in the reaction is the ring opening of $\mathrm{CL}$ with water to aminocapronic acid $(\mathrm{ACA})^{13}$. At atmospheric pressure the reaction times at $260^{\circ} \mathrm{C}$ are in the order $16 \mathrm{~h}$. The reaction times can be considerably shortened by increasing the water concentration during the ring-opening step. To do this the first step has to be carried out under pressure. If ACA is used as initiator (few per cent), the slow lactam ring-opening step can be avoided and the polymerization rates are much higher ${ }^{13}$.

To obtain, with a reactor process, blends with a small particle size of the rubbery phase, a few approaches are possible. One can dissolve the rubber in the starting reaction mass and let it phase-separate out during the polymerization; one can temporarily lower the viscosity of the rubber; and one can add preshaped particles.

The solvent method approach was followed for ethylene-propylene monomer (EPM) rubbers ${ }^{9,10}$. D'Orazio 


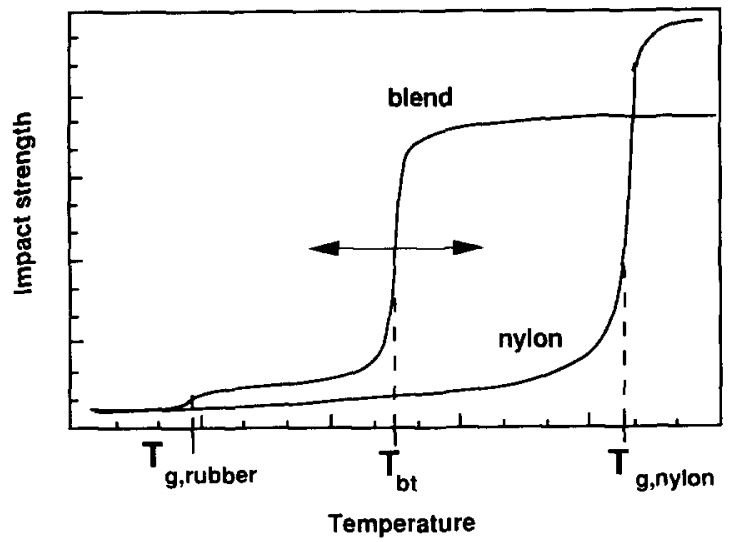

Figure 1 Schematic picture of impact behaviour of a polyamide and a polyamide blend

et $a l^{9}$ and Cimmino et al. ${ }^{10}$ dissolved an EPM rubber in xylene and added this to a caprolactam-water mixture. Their polymerization was carried out at $260-270^{\circ} \mathrm{C}$, for $4 \mathrm{~h}$ under vigorous stirring. Rubber particle sizes of $1-20 \mu \mathrm{m}$ were obtained. The impact behaviour of these reactor blends was comparable to that of extrusion blends having the same rubber particle size.

With emulsion polymerization, emulsions of small rubbery particles in water can be obtained. The particles can be stabilized by giving them a hard shell, forming core-shell particles, e.g. acrylate rubber/PMMA (poly(methyl methacrylate)) and polybutadiene/SAN (styrene-acrylonitrile). These core-shell impact modifiers (CSIM) have a rubbery core and a hard shell, and are usually supplied as agglomerates. In a reactor blending process these agglomerates have to be broken up and dispersed. Udipi et al. ${ }^{11.12}$ have shown that, without any specific interactions between CSIM and the reaction mass, this breaking up in the reactor is only partial. On subsequent injection moulding the dispersion is better. The dispersion could be improved by modifying the shell $^{11.12}$. By starting from a latex of CSIM particles, an aggregate-free system was obtained ${ }^{11}$.

The aim of this work is to study whether, with a reactor blending process, a good dispersion of the acrylic CSIM in a PA6 matrix can be obtained. The impact behaviour of these reactor bends will be evaluated and compared with that of extrusion blends.

\section{EXPERIMENTAL}

\section{Materials}

The suppliers of the materials were as follows: caprolactam (CL), DSM, Geleen, The Netherlands; aminocapronic acid (ACA), Merck, Darmstadt, Germany; PA6, K 124, $\eta_{\text {rel }}=2.4$, and M258, $\eta_{\text {rel }}=5.8$ (both $1 \%$ solutions in $98 \% \mathrm{H}_{2} \mathrm{SO}_{4}$ ), Akzo, Arnhem, The Netherlands; Paraloid EXL2300 acrylic CSIM (powder), and Paraloid EXL2386 acid-modified acrylic CSIM (powder), Rohm \& Haas SA, France. All the materials were used as received.

\section{Methods}

Extrusion blending. PA6 and CSIM were blended in a co-rotating twin-screw extruder (Berstorff ZE 25, Hanover, Germany). The blending was carried out at standard conditions and at high-shear conditions. For the standard conditions the blending was at $100 \mathrm{rev} \mathrm{min}^{-1}$, a throughput of $2 \mathrm{~kg} \mathrm{~h}^{-1}$ and with the temperature settings $280-280-280-280-290-290-290^{\circ} \mathrm{C}$. For the highshear conditions the compounding was at $400 \mathrm{rev} \mathrm{min}^{-1}$, a throughput of $2 \mathrm{~kg} \mathrm{~h}^{-1}$ and with the temperature settings $240-240-240-240-250-250-250^{\circ} \mathrm{C}$.

Injection moulding. Izod test bars $\left(10 \times 4 \times 80 \mathrm{~mm}^{3}\right)$ of the dried polymers were injection moulded (Arburg Allrounder 221-55-250) with the temperature settings of $260-260-260-260-290^{\circ} \mathrm{C}$ and the mould at $90^{\circ} \mathrm{C}$. The notched Izod strength was measured on test bars with a machined notch (ISO 180/1A) and determined after drying the samples $\left(16 \mathrm{~h}\right.$ in a vacuum oven at $\left.110^{\circ} \mathrm{C}\right)$.

Melt flow index (MFI). The melt flow index (MFI) of the dried polymers was determined according to ASTM-D $1238-65 \mathrm{~T}$ at $250^{\circ} \mathrm{C}$.

Dynamic mechanical spectrometry (d.m.s.). With a $25 / 50 \mathrm{~mm}$ parallel-plate system, the rheological behaviour of the melt was studied with a Rheometrics RMS800 in the temperature range of $230-300^{\circ} \mathrm{C}$.

Dynamic mechanical thermal analysis (d.m.t.a.). The torsional properties were studied with a Myrenne ATM3 (Germany) on dried test bars $\left(80 \times 10 \times 2 \mathrm{~mm}^{3}\right)$ at $1 \mathrm{~Hz}$ with a heating rate of $2^{\circ} \mathrm{C} \mathrm{min}^{-1}$.

Scanning electron microscopy (SEM). The samples were cut with a LKB Nova cryomicrotome at $-100^{\circ} \mathrm{C}$. The rubber in the surface was extracted with boiling xylene $(24 \mathrm{~h})$. After drying, the sample was gold coated and studied with a SEM (JEOL JSM-35-CF).

\section{Polymerizations}

Water-initiated $(10 \%$ CSIM). A 1 litre stirred autoclave (Juchheim, Germany) is charged with $360 \mathrm{~g} \mathrm{CL}$ and $18 \mathrm{ml}$ distilled water $(5 \mathrm{wt} \%)$ warmed to $80^{\circ} \mathrm{C}$. As soon as the CL has melted, $40 \mathrm{~g}$ of CSIM was added. After flushing with nitrogen the reactor is closed and a nitrogen starting pressure of 5 bar is imposed. The reaction mass is heated for $20 \mathrm{~min}$ at $200^{\circ} \mathrm{C}$ and $1 \mathrm{~h}$ at $270^{\circ} \mathrm{C}$, during which the maximum pressure was held at 15 bar. Subsequently the pressure was reduced to atmospheric and held at that pressure for $5.5 \mathrm{~h}$ and $270^{\circ} \mathrm{C}$. After the reaction mass was cooled, the sample was granulated. Free CL in the sample was extracted with boiling methanol $(24 \mathrm{~h})$.

Aminocapronic acid-initiated (10\% CSIM). A 1 litre stirred autoclave (Juchheim, Germany) is charged with $326 \mathrm{~g} \mathrm{CL}$ and $41.7 \mathrm{~g}$ aminocapronic acid (ACA) warmed to $80^{\circ} \mathrm{C}$. As soon as the $\mathrm{CL}$ has melted, $40 \mathrm{~g}$ of CSIM was added. The reaction mass is heated for $1 \mathrm{~h}$ at $190^{\circ} \mathrm{C}$ and $5 \mathrm{~h}$ at $240^{\circ} \mathrm{C}$ at atmospheric pressure. After the reaction mass was cooled, the sample was granulated. Free $C L$ in the sample was extracted with boiling methanol $(24 \mathrm{~h})$.

Adding CSIM to prepolymer. A 1 litre stirred autoclave (Juccheim, Germany) is charged with $360 \mathrm{~g} \mathrm{CL}$ and $18 \mathrm{ml}$ distilled water $(5 \mathrm{wt} \%)$. After flushing with nitrogen the reactor is closed and a nitrogen starting pressure of 5 bar is imposed. The reaction mass is heated for $20 \mathrm{~min}$ at $200^{\circ} \mathrm{C}$ and $1 \mathrm{~h}$ at $270^{\circ} \mathrm{C}$, during which the maximum pressure was held at 15 bar. Subsequently the pressure 
was reduced to atmospheric. At this point the prepolymer has $\eta_{\text {inh }}$ of 1.3. To the stirred melt is added $40 \mathrm{~g}$ of CSIM and reacted for $4.5 \mathrm{~h}$ and $270^{\circ} \mathrm{C}$ at atmospheric pressure. After the reaction mass was cooled, the sample was granulated. Free $C L$ in the sample was extracted with boiling methanol $(24 \mathrm{~h})$.

A prepolymer with $\eta_{\text {inh }}$ of 1.6 was obtained by heating the $\mathrm{CL}$-water reaction mass for $20 \mathrm{~min}$ at $200^{\circ} \mathrm{C}$ and $1 \mathrm{~h}$ at $270^{\circ} \mathrm{C}$, during which the maximum pressure was held at $15 \mathrm{bar}$, and subsequently $1 \mathrm{~h}$ at $270^{\circ} \mathrm{C}$ at atmospheric pressure. After adding the CSIM the reaction at $270^{\circ} \mathrm{C}$ was continued for another $3.5 \mathrm{~h}$.

Degree of grafting ${ }^{14}$. A sample, $5 \mathrm{~g}$, is suspended in $100 \mathrm{ml} 98 \%$ formic acid for $24 \mathrm{~h}$. The suspension was centrifuged at $15000 \mathrm{rev} \mathrm{min}^{-1}$ and the clear underlayer removed with a syringe. The remaining non-dissolved part is resuspended in formic acid. This procedure is repeated three times. The final residue is washed with water, dried and analysed by elemental analysis (the percentage of nitrogen $(\mathrm{N} \%))$. The PA content is calculated from $\mathrm{N} \%$ using $(\mathrm{N} \% / 14) \times 113.2(\mathrm{~mol}$ wt $\mathrm{PA}$ repeat).

Stability of CSIM. A 1 litre stirred autoclave (Juccheim, Germany) is charged with $40 \mathrm{~g}$ CSIM and $18 \mathrm{ml}$ distilled water. After flushing with nitrogen the reactor is closed and a nitrogen starting pressure of 5 bar is imposed. The reaction mass is heated for $5 \mathrm{~h}$ at $270^{\circ} \mathrm{C}$, during which the maximum pressure was held at 15 bar. A film and a bar of this material were melt pressed. The hydrolysis of the acrylic ester was studied on a film with a Biorad FTIR, 16 scans for each spectrum. The bar was analysed with d.m.t.a.

\section{RESULTS}

\section{Extrusion blends}

PA6 and acrylic CSIMs were blended with a twin-screw extruder. Two types of impact modifiers were used, one with an acrylic ester shell (unmodified, EXL2300) and one with an acrylic shell with some free acid groups

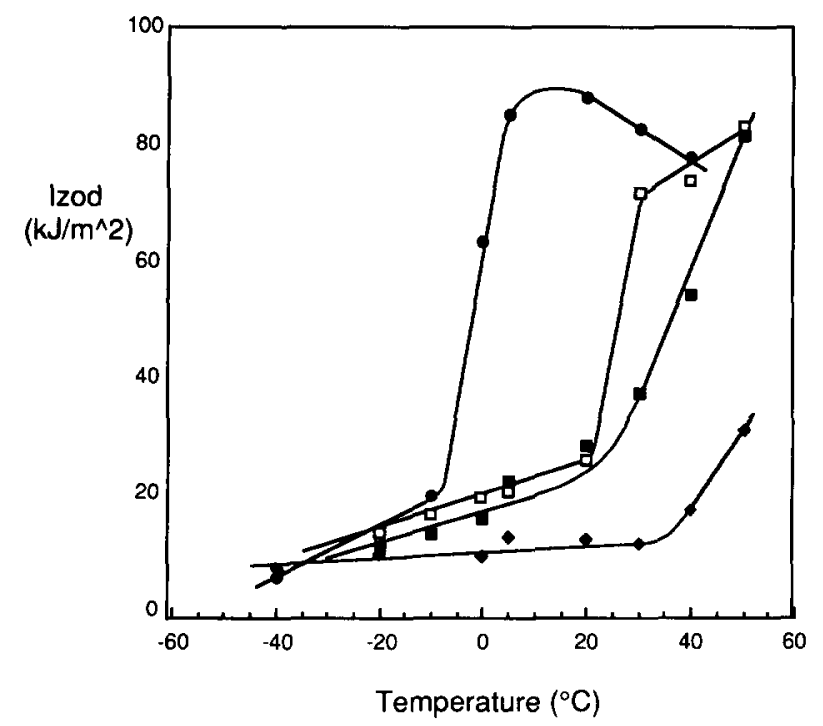

Figure 2 Impact behaviour of extrusion blends of PA2.4 and an unmodified CSIM (EXL2300). CSIM concentration (wt \%): (\$) 10\%; (ㅁ) $20 \%$; (๑) $30 \%$; (口) $40 \%$

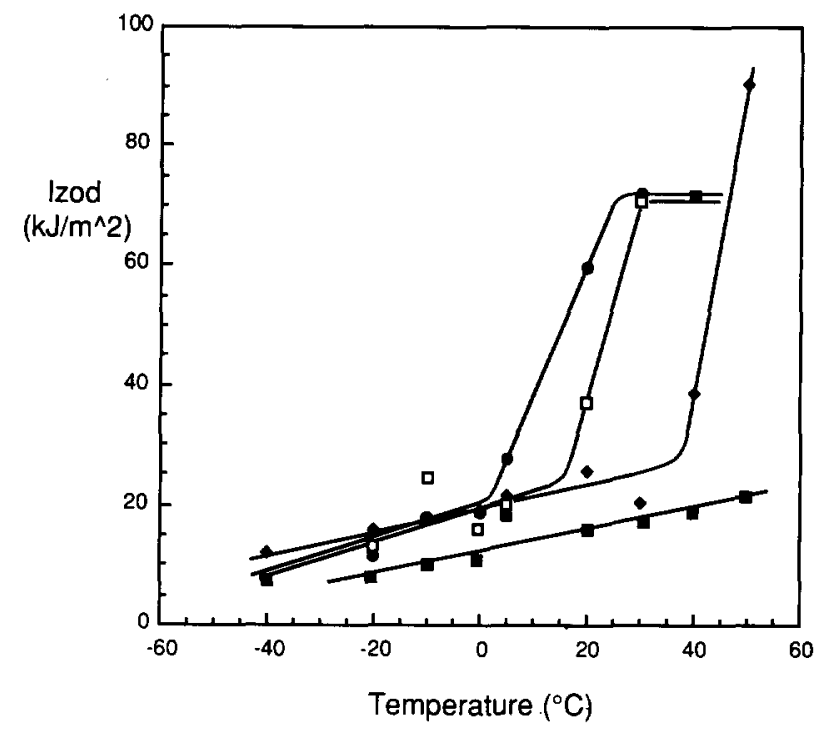

Figure 3 Impact behaviour of extrusion blends of PA2.4 and a modified CSIM (EXL2386). CSIM concentration (wt \%): (\$) 10\%; (口) $20 \%$; ( ) $30 \%$; (口) $40 \%$

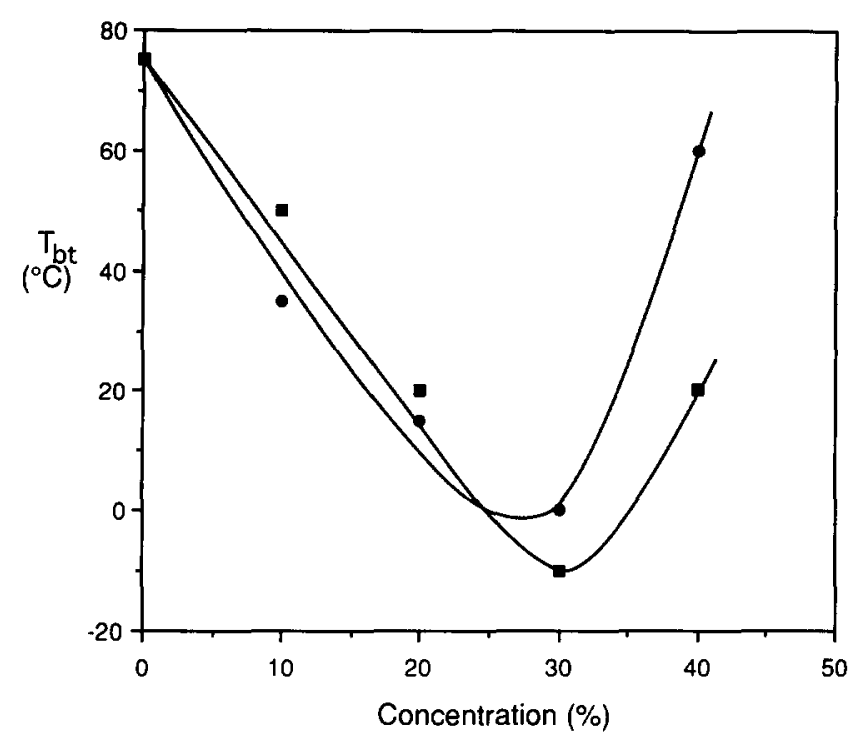

Figure 4 Brittle-tough transition temperature of the blends as a function of the CSIM concentration (wt\%): ( $(\mathbf{0})$ unmodified CSIM (EXL2300); (๑) modified CSIM (EXL2386)

(modified, EXL2386). In the blending operation the CSIM agglomerates break up into primary particles. The particle size was found to be $0.32 \mu \mathrm{m}$ for the EXL2300 and $0.30 \mu \mathrm{m}$ for the EXL2386, both with a narrow size distribution. Changing the blending conditions to "highshear' conditions did not change the particle size. With CSIM only the agglomerates have to be broken up. The primary particles are not expected to be broken up and also coalescence is not expected to take place.

With these CSIMs, tough blends can be made (Figures 2 and 3). The impact levels in the brittle region can rise up to $20 \mathrm{~kJ} \mathrm{~m}^{-2}$ and in the tough region up to $70 \mathrm{~kJ} \mathrm{~m}^{-2}$. These values are comparable to other PA-rubber blends. Most important in toughened blends is the shift in the brittle-to-tough transition. At a CSIM concentration up to $30 \%$ the brittle-to-tough transition temperature $\left(T_{\mathrm{bt}}\right)$ decreases linearly with concentration (Figure 4). Unexpected is the behaviour of the $40 \%$ blends, 
Blends of PA6 with acrylic CSIM: R. J. Gaymans and J. W. van der Werff

Table 1 PA6/modified CSIM (EXL2386) blends (90/10)

\begin{tabular}{lllllll}
\hline No. & PA initial & $\begin{array}{l}\text { Conditions } \\
\left(\mathrm{h} /{ }^{\circ} \mathrm{C} / \mathrm{bar}\right)\end{array}$ & $\begin{array}{l}\text { PA } \\
\eta_{\text {rel }}\end{array}$ & $\begin{array}{l}M F I \text { blend } \\
(\mathrm{g} / 10 \mathrm{~min})\end{array}$ & $\begin{array}{c}\text { Dispersion } \\
\left(\mathrm{kJ} \mathrm{m} \mathbf{m}^{-2}\right)\end{array}$ \\
\hline 1 & Polymer, $\eta_{\mathrm{rel}}=2.4$ & Extruder, $6 \mathrm{~min} / 260^{\circ} \mathrm{C}$ & 2.4 & - & No clusters & 25.5 \\
2 & $\mathrm{CL} / \mathrm{H}_{2} \mathrm{O}$ & Reactor, $1 / 250 / 15+5.5 / 250 / 1$ & 1.8 & $\ll 1$ & No clusters & 7.0 \\
\hline
\end{tabular}

Table 2 PA6/unmodified CSIM (EXL2300) blends (90/10)

\begin{tabular}{|c|c|c|c|c|c|c|c|}
\hline No. & PA initial & $\begin{array}{l}\text { Conditions } \\
\left(\mathrm{h} /{ }^{\circ} \mathrm{C} / \text { bar }\right)\end{array}$ & $\begin{array}{l}\text { PA } \\
\eta_{\text {rel }}\end{array}$ & $\begin{array}{l}M F I \text { blend } \\
(\mathrm{g} / 10 \mathrm{~min})\end{array}$ & $\begin{array}{l}\text { Graft con. } \\
(\%)\end{array}$ & Dispersion & $\begin{array}{l}\text { Izod } \\
\left(\mathrm{kJ} \mathrm{m}^{-2}\right)\end{array}$ \\
\hline 3 & Polymer, $\eta_{\mathrm{rel}}=2.4$ & Extruder, $6 \mathrm{~min} / 260^{\circ} \mathrm{C}$ & 2.4 & 6.6 & 2.5 & No clusters & 10.5 \\
\hline 4 & Polymer, $\eta_{\mathrm{rel}}=5.8$ & Extruder, $6 \mathrm{~min} / 260^{\circ} \mathrm{C}$ & 5.8 & - & - & No clusters & 17.0 \\
\hline 5 & $\mathrm{CL} / \mathrm{H}_{2} \mathrm{O}$ & Reactor, $1 / 250 / 15+5.5 / 250 / 1$ & 1.8 & 1 & 29.8 & No clusters & 8.5 \\
\hline 6 & $\mathrm{CL} / \mathrm{H}_{2} \mathrm{O}$ & Reactor, $1 / 250 / 15+5.5 / 250 / \mathrm{N}_{2}$ & 2.4 & $\ll 1$ & 40.8 & No clusters & 7.5 \\
\hline 7 & $\mathrm{CL} / \mathrm{H}_{2} \mathrm{O}$ & Reactor, $1 / 270 / 15+5.5 / 270 / \mathbf{N}_{2}$ & 3.2 & $\ll 1$ & 81.7 & No clusters & 11.0 \\
\hline 8 & Polymer, $\eta_{\mathrm{rel}}=1.3$ & Reactor, $4.5 / 270 / \mathrm{N}_{2}$ & 3.2 & 0.3 & - & Clusters & 6.0 \\
\hline 9 & Polymer, $\eta_{\mathrm{rel}}=1.6$ & Reactor, $3.5 / 270 / \mathrm{N}_{2}$ & 3.2 & 0.6 & - & Clusters & 5.5 \\
\hline 10 & CL/ACA & Reactor, $1 / 190 / 1+5 / 240 / 1$ & 2.7 & 5.0 & - & No clusters & 12.5 \\
\hline
\end{tabular}

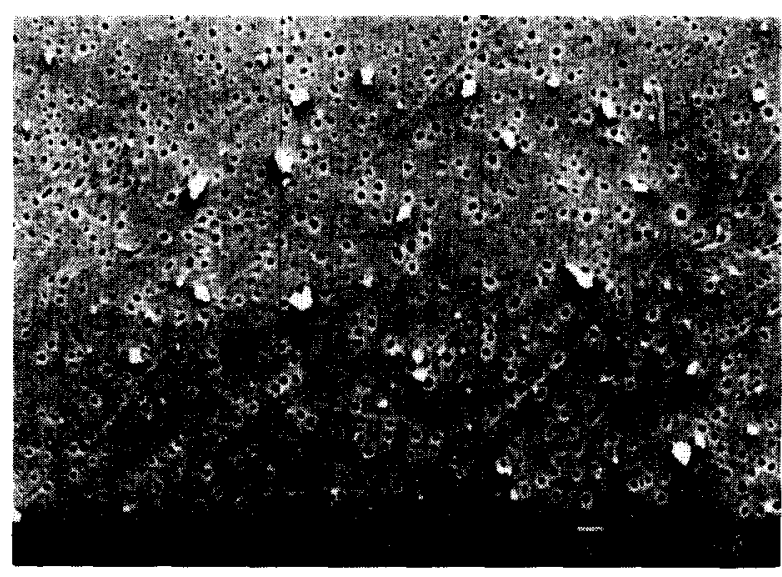

Figure 5 SEM analysis of sample 5, CSIM well dispersed

which have a very high $T_{\mathrm{bt}}$ again. In these $40 \%$ blends the CSIM have coagulated to $>1 \mu \mathrm{m}$ particles. This effect is to some extent already taking place in the $30 \%$ modified CSIM blend. The modified CSIM appears to be somewhat more effective at low concentrations.

\section{Reactor blends}

The CSIM seem to be interesting modifiers for reactor blends as they have a fine particle size and the CSIM agglomerates are easily broken up. The reactor blends were prepared in a stirred autoclave. In the first set of experiments (water-initiated) a calculated $\eta_{\text {rel }}$ of the PA of 1.8 was obtained ${ }^{13}$. This is lower than the 2.4 used for extrusion blending (Table I).

The $10 \%$ acid-modified CSIM, water-initiated polymerization. With 10\% CSIM EXL2386 (acidmodified), extremely viscous blends were obtained (very low $M F I$ values) (Table $l$ ). SEM analysis showed that the CSIM agglomerates were broken up and evenly distributed. The impact strength was, however, low. Although the PA was short-chained (calculated $\eta_{\text {rel }}$ of 1.8 ), the whole system seems to have gelled. For these reaction conditions, the acid-modified CSIM was too reactive and was not studied further.

The $10 \%$ unmodified CSIM, water-initiated polymerization. The reactor blend with $10 \%$ unmodified CSIM (EXL2300) was viscous but had not gelled (Table 2, No. 5). The CSIM agglomerates had been broken up and the particles were well dispersed (Figure 5). The notch impact strength was lower than that of the respective extrusion blends (Nos. 3 and 4). Changing the reaction conditions to obtain higher calculated PA molecular weights (Table 2, Nos. 6 and 7) decreased the $M F I$ strongly and improved the impact strength. The molecular weight of the PA seems to be an important factor determining the impact strength (see also Table 2, Nos. 3 and 4).

The analysis of the degree of grafting of PA onto CSIM showed that extrusion blending leads to a low degree of grafting (Table 2, Nos. 3 and 4). Reactor blends (Nos. 5-7), however, display a much higher degree of grafting. The degree of grafting increased with the severity of the reaction conditions. With the high amount of grafting found for certain reactor blends it seems unlikely that this is only due to surface grafting reactions. In the reactions 5-7 the CSIM is added to the lactam, and as the lactam has a high solvation power it might have not only broken up the agglomerates but also dissolved some CSIM.

CSIM addition to prepolymer. Addition of the CSIM in a later stage of the polymerization reduces the solvation power. In the blends Nos. 8 and 9, the CSIM were added to prepolymers. This increased the MFI of the obtained blends but the CSIM agglomerates were now not broken up (Figure 6). The notched Izod impact strength was at a low level, which is not surprising. To obtain primary particles, it seems important to add the CSIM at the beginning of the reaction. To reduce the degree of grafting, the reaction conditions must be milder. Particularly, the initial stage of polymerization seems to be critical. 
Table 3 PA6/unmodified CSIM (EXL2300) blends (80/20)

\begin{tabular}{|c|c|c|c|c|c|c|}
\hline No. & PA initial & $\begin{array}{l}\text { Conditions } \\
\left(\mathrm{h} /{ }^{\circ} \mathrm{C} / \mathrm{bar}\right)\end{array}$ & $\begin{array}{l}\text { PA } \\
\eta_{\text {rel }}\end{array}$ & $\begin{array}{l}M F I \text { blend } \\
(\mathrm{g} / 10 \mathrm{~min})\end{array}$ & Dispersion & $\begin{array}{l}\text { Izod } \\
\left(\mathrm{kJ} \mathrm{m}^{-2}\right)\end{array}$ \\
\hline 11 & Polymer, $\eta_{\text {rel }}=2.4$ & Extruder, $6 \mathrm{~min} / 260^{\circ} \mathrm{C}$ & 2.4 & - & No clusters & 22.0 \\
\hline 12 & CL/ACA & Reactor, $1 / 190+5 / 240$ & 2.7 & $\ll 1$ & Some clusters & 8.5 \\
\hline 13 & CL/ACA & Reactor, $1 / 190+1 / 240$ & 1.6 & 0.8 & Some clusters & 3.0 \\
\hline 14 & CL/ACA & Reactor, $0.5 / 190+0.5 / 240 / 1$ & 1.4 & 3.6 & Some clusters & 2.5 \\
\hline
\end{tabular}

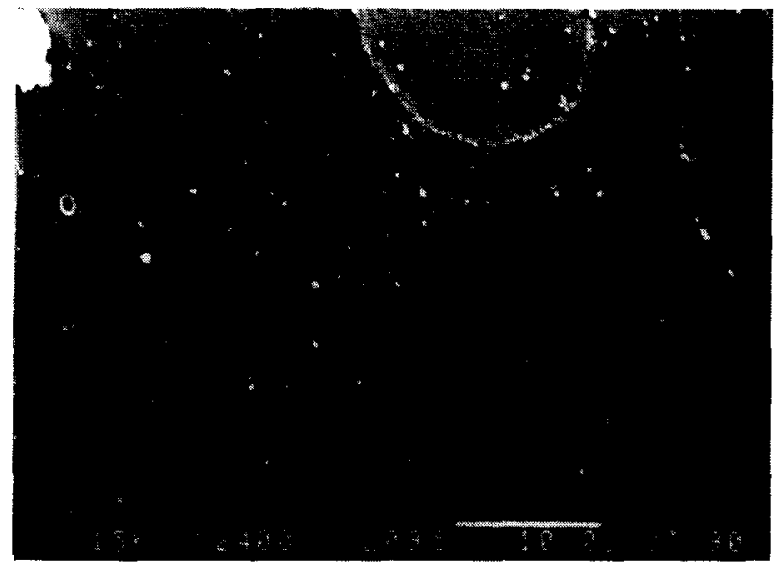

Figure 6 SEM analysis of sample 8, CSIM in clusters

Aminocapronic acid-initiated polymerization. The severity of the reaction conditions can be decreased considerably by initiating the reaction with ACA instead of water ${ }^{13}$. In this way the slow conversion of CL with water to ACA is left out and no autoclave step is needed. Reacting for $1 \mathrm{~h}$ at $190^{\circ} \mathrm{C}$ and $5 \mathrm{~h}$ at $240^{\circ} \mathrm{C}$ at atmospheric pressure gives a calculated $\eta_{\text {rel }}$ of 2.7 (No. 10). The reactor blends with $10 \%$ EXL2300 under these conditions resulted in a $M F I$ of $5 \mathrm{~g} / 10 \mathrm{~min}$. The CSIM particles were well dispersed. The notched Izod value was comparable to the extrusion blend (No. 3).

The 20\% unmodified CSIM, ACA-initiated. Increasing the CSIM concentration to $20 \%$, with the reaction conditions of No. 10, yielded a very low MFI (Table 3, No. 12). The impact strength was lower than that of the $10 \%$ reactor blend No. 10 or the $20 \%$ extrusion blend No. 11. By reducing the reaction time (Nos. 13 and 14) the $M F I$ value could be increased. However, the impact strength was low, lower than for No. 12. For reactor blends with $20 \%$ CSIM, a combination of good dispersion, high $M F I$ and high Izod value has not yet been obtained.

\section{Reactor blend process}

Addition of the CSIM to the CL instead of to the prepolymer or the polymer gave much lower $M F I$ values. We observed also that adding the CSIM to the CL strongly increased the viscosity of the lactam mixture. So the acrylic partially dissolves in the lactam. This is in agreement with the findings of Udipi, who observed that the shell of an acrylic core-shell material dissolved in the lactam $^{11}$. The lactam helps to deagglomerate the clusters but also dissolves some of the acrylic shell material. At these reaction conditions the amine end-group of the PA can react with the acrylic group of the dissolved acrylic. Each PA6 chain contains only one amine group and each acrylic polymer chain contains many acrylic groups. If several PA6 chains are grafted on the acrylic, comb-like structures are formed. It is expected that these comb-like structures give the reactor blends such high viscosities.

\section{Stability of CSIM}

Another question is whether the CSIM can withstand the reaction conditions without hydrolysis or thermal degradation. The CSIM (EXL2300) was kept for $5 \mathrm{~h}$ at $270^{\circ} \mathrm{C}$ and 15 bar steam pressure in an autoclave. A film and a bar of this material were melt pressed. The i.r. spectrum of the treated material had the same peak positions as the untreated material. The relative peak strength of the shoulder at $1692 \mathrm{~cm}^{-1}$ assigned to the free acid increased with the steam treatment (Figure 7).

The d.m.t.a. data showed that the $G^{\prime}$ modulus of the steam-treated CSIM, was over the temperature interval -100 to $+100^{\circ} \mathrm{C}$, somewhat lower (Figure 8). The $T_{8}$ values at $-42^{\circ} \mathrm{C}$ and $110^{\circ} \mathrm{C}$ had not shifted. The reaction conditions do not seem to have changed the rubbery character of the CSIM but the acid content is increased.

\section{Rheological behaviour}

The $M F I$ data are low for the calculated $\eta_{\text {rel }}$. The viscoelastic behaviour of two samples (Table 2, Nos. 10 and 12) was studied in more detail with d.m.s. in the temperature region $230-300^{\circ} \mathrm{C}$. For linear polymers the phase angle increases with decreasing frequency to a value of $90^{\circ}$ (Newtonian). The phase angle as a function of frequency of sample 10 is given in Figure 9. This phase angle is, in the whole frequency and temperature region, clearly non-Newtonian. It is evident too that the material with increasing temperature becomes more elastic. It even seems that the material is crosslinking during the experiment.

The phase angle measurements of a $20 \%$ blend (sample 12) show an even stronger elastic effect (Figure 10). The upswing at $300^{\circ} \mathrm{C}$ and low frequencies suggests a disentanglement of the network and thus that a transient network was present. With these elastic effects it is not surprising that the $M F I$ values are so low.

\section{CONCLUSIONS}

Acrylic core-shell impact modifiers can easily be deagglomerated by twin-screw extrusion blending. The observed particle sizes were independent of processing conditions. The notched impact behaviour is similar to that of other PA-rubber blends. The effect of toughening efficiency seems to be a shift in the brittle-to-tough transition temperature. With increasing 


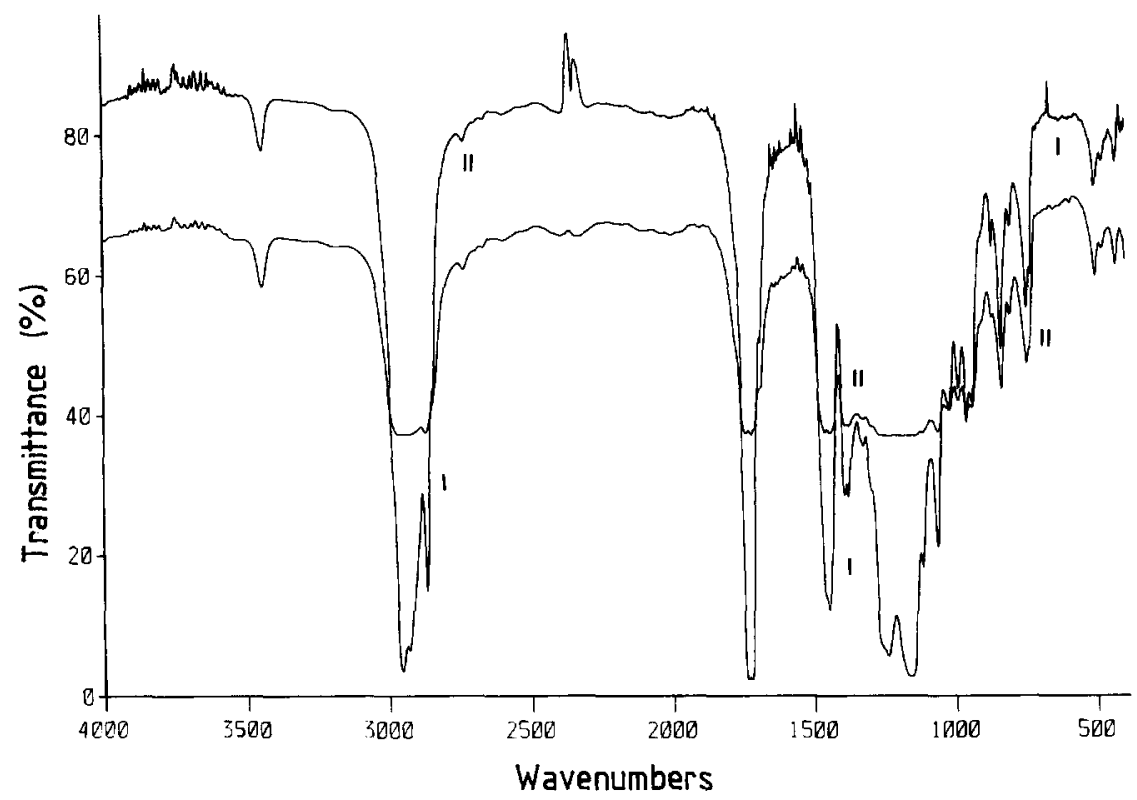

Figure 7 I.r. spectrum of EXL2300: (I) as obtained; (II) after steam treatment $\left(5 \mathrm{~h}, 270^{\circ} \mathrm{C}\right.$ )

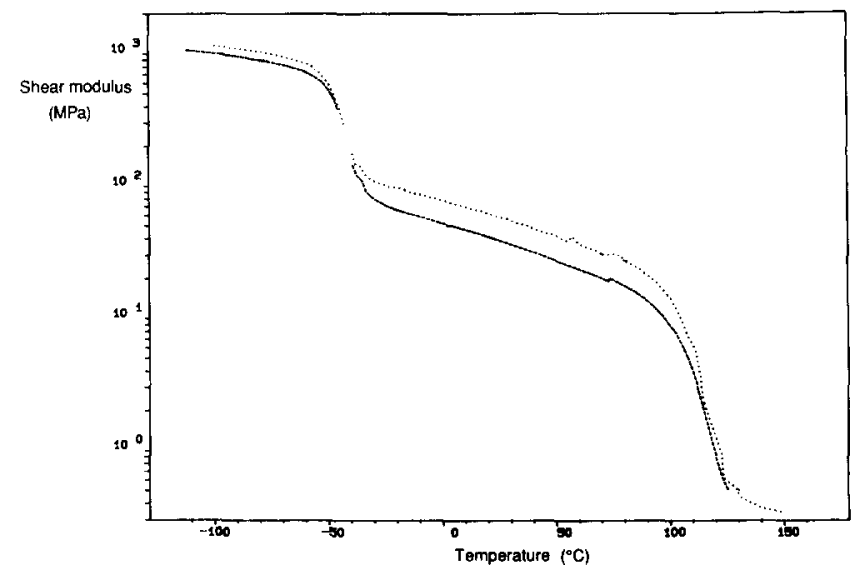

Figure 8 Shear modulus vs. temperature of EXL2300: $(\cdots)$ as obtained; $(\longrightarrow)$ after steam treatment

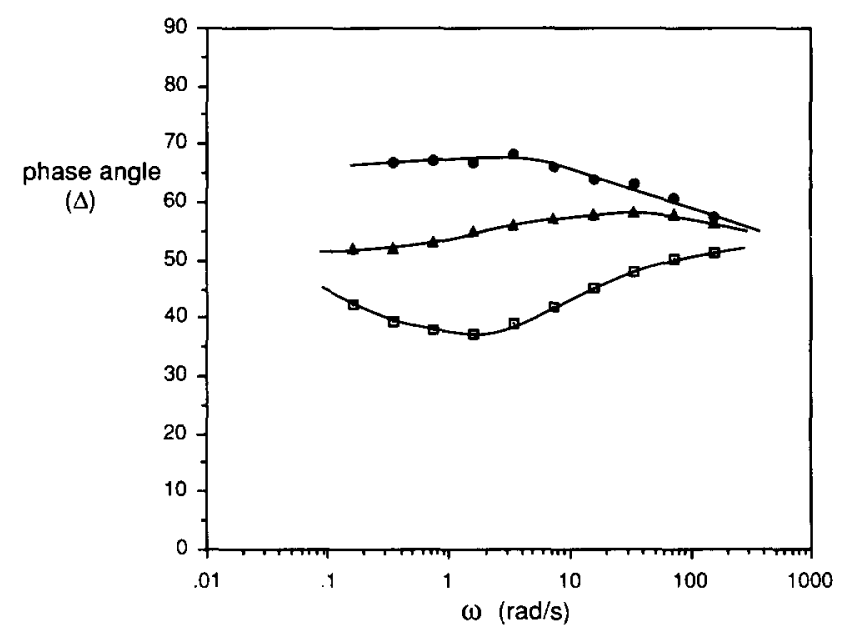

Figure 9 Melt rheological phase angle vs. frequency of blend No. 10:

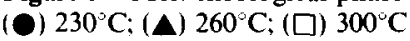

CSIM concentration, this $T_{\mathrm{bt}}$ is decreased. The $40 \%$ blends coalesced. At low concentrations the modified CSIM seem to be slightly more effective. Some grafting of the PA on the unmodified CSIM particle takes place

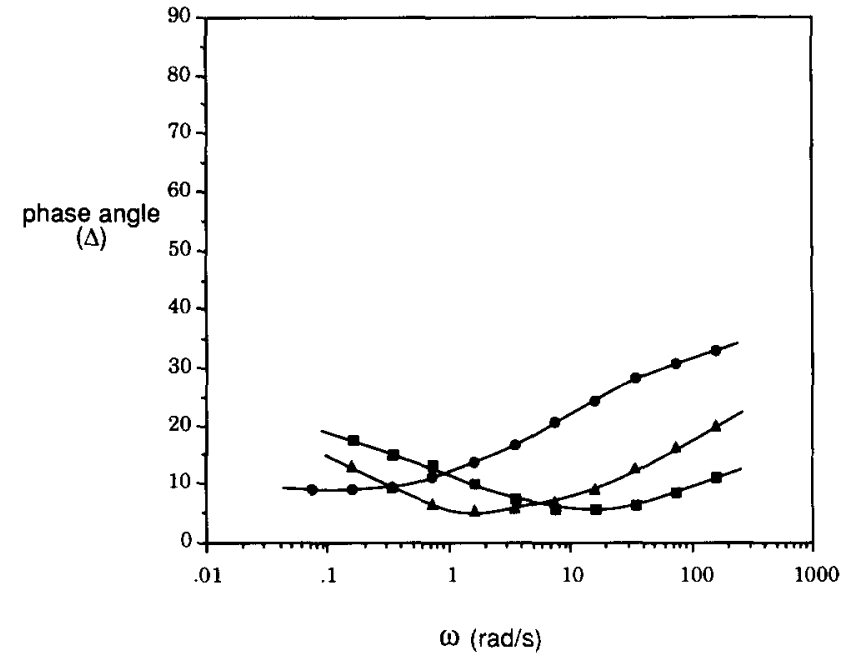

Figure 10 Melt rheological phase angle vs. frequency of blend No. 12:

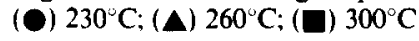

during extrusion compounding. CSIM particles seem to be ideal for reactor blends, as the preshaped particles have only to be dispersed.

For a good deagglomeration of CSIM in a PA6 reactor process, the material has to be added to the lactam. Adding the particles to the prepolymers did not give a good deagglomeration. The lactam is a strong solvent and it dissolves some of the CSIM. At a later stage in the PA polymerization a reaction between the acrylic or the hydrolysed acrylic and the PA6 growing chain is possible. Not only is the PA grafted on the particle surface, but probably also some grafted PA is grafted on dissolved acrylic chains forming comb-like structures in the matrix.

At severe reaction conditions, systems with a very low MFI were obtained. The polymer melt was clearly non-Newtonian and has a strong elastic component at low shear rates, suggesting that a transient network was formed. This is in agreement with the possible formation of comb-like structures in the system.

For a given length of the PA chain and having a deagglomerated CSIM system, the impact values of the 
reactor blends were comparable to those of extrusion blends. In future studies on reactor blends with these acrylic core-shell systems, one should avoid dissolving the acrylic CSIM but still break up the agglomerates.

\section{ACKNOWLEDGEMENTS}

This work is part of the research programme of the University of Twente and was financially supported by DSM Research, The Netherlands. The authors wish to thank Dr C. Koning (DSM) for his active interest in the project and Mr J. Palmen (DSM) for the melt rheological analysis.

\section{REFERENCES}

1 von Flexman, E. A. Kunststoffe 1979, 69, 172
Wu, S. Polymer 1985, 26, 1855

3 Borggreve, R. J. M., Gaymans, R. J., Schuijer, J. and Ingen Housz, A. J. Polymer 1987, 28, 1489

4 Oostenbrink, A. J., Molenaar, L. J. and Gaymans, R. J., PRI Conf. Polymer Blends, Cambridge, July 1990, Paper E3

5 Borggreve, R. J. M., Gaymans, R. J. and Schuijer, J. Polymer 1989, 30, 71

6 Dijkstra, K. and Gaymans, R. J. Polymer 1994, 35, 332

7 Sederel, L. C., Mooney, J. and Weese, R. H. Polymer Blends and Alloys Conf., Strasbourg, June 1987

8 Leblanc, D., Reginster, L. and Sederel, L. C. Compalloy 90, London, January 1990

9 D'Orazio, L., Mancarella, C. and Martuscelli, E. J. Mater. Sci. 1988, 23, 161

10 Cimmino, S., D’Orazio, L., Grego, R., Maglio, G., Malinconico, M., Mancarella, C., Martuscelli, E., Musto, P., Palumbo, R. and Ragosta, G. Polym. Eng. Sci. 1985, 25, 193 Udipi, K. J. Appl. Polym. Sci. 1988, 36, 117 Lefelar, J. A. and Udipi, K. Polym. Commun. 1989, 30, 38 Reimschüssel, K. H. J. Polym. Sci., Macromol. Rev. 1977, 12, 65 Borggreve, R. J. M. and Gaymans, R. J. Polymer 1989, 30, 63 